\title{
Evaluation of Weld Line Strength in Low Density Polyethylene Specimens by Optical Microscopy and Simulation
}

\author{
Tan Yizong, Zulkifli Mohamad Ariff* and Khoo Guo Liang \\ School of Materials and Mineral Resources Engineering, \\ Universiti Sains Malaysia, Engineering Campus, \\ 14300 Nibong Tebal, Pulau Pinang, Malaysia \\ *Corresponding author: zulariff@usm.my
}

Published online: 15 April 2017

To cite this article: Tan Yizong, Zulkifli Mohamad Ariff and Khoo Guo Liang. (2017). Evaluation of weld line strength in low density polyethylene specimens by optical microscopy and simulation. Journal of Engineering Science, 13: 53-62, https://doi.org/10.21315/jes2017.13.4.

To link to this article: https://doi.org/10.21315/jes2017.13.4

\begin{abstract}
Investigation on the effect of different processing parameters onto injection moulded low density polyethylene (LDPE) had been done. The LDPE was moulded into dumbbell shape with weld line to better understand the flow front of the polymer melt and where two flow fronts meet. Three parameters were chosen to shear modify the LDPE, which were injection speed, injection pressure and mould temperature. Tensile testing was being done onto the dumbbell samples to evaluate the strength of the weld line produced. Differential Scanning Calorimetry was being done onto the weld line region to obtain the degree of crystallinity but was found to be not a good method for strength evaluation. Measurement of the thickness of the weld line under optical microscope showed that it was related to the tensile strength of the dumbbell samples with inverse relationship. Simulation of the polymer melt flow was also being done using CADMOULD to visualise the effect of the chosen processing parameters onto the polymer flow front and was found to be able to evaluate the weld line strength.
\end{abstract}

Keywords: Low density polyethylene, weld line, injection speed, injection pressure, mould temperature, CADMOULD

\section{INTRODUCTION}

Polymeric materials had been used to replace many other materials such as metal, wood and glass in manufacturing products in modern industries due to several advantages of polymeric materials. ${ }^{1}$ Injection moulding is, among many fabrication methods, able to manufacture products having complex structure with precious dimension in high efficiency with its fully automated processing cycle. ${ }^{2}$ 
The polymer processing parameters such as injection pressure, moulding temperature and injection speed will lead to difference in orientation of the polymer chains, residual stress, molecular degradation and degree of crystallisation of the final polymer product ${ }^{3}$ and to further complicating the situation, the shear modification will recover with time depending on the molecular structure of that particular polymer. ${ }^{4,5}$ The structural change in polymer caused by the complicated polymer melt flow as mentioned above will ultimately influence the final properties of the product. ${ }^{6-9}$

Without a thorough understanding of what happens to the polymer melt flow in the mould cavity, the properties of polymer products are hard to predict, even so in the polymer industry where normally trial and error is being practiced to achieve a desirable product. It is understandable that with profit in mind, trial and error without much studying of the issue is quite favourable, but a good understanding of how the polymer melt behave is beneficial in a long run.

One of the problems in understanding how the polymer melt behave during injection moulding is the issue of observing the melt flow in the cavity. This problem of monitoring flow inside the obscured mould cavity during the fast process can be achieved by the assistance of computer-aided mould filling simulation. Although the exact condition cannot be mimicked, ${ }^{10,11}$ but simulation of the polymer melt provide much information that can be related with the experimental results obtained.

\section{EXPERIMENTAL}

\subsection{Material and Sample Preparation}

Low density polyethylene (LDPE) was chosen to be the representative of polymers and subject of investigation in this study. The LDPE resin was provided by Lotte Chemical with the code TITANLENE LDF $200 \mathrm{YZ}$.

Dumbbell samples were produced with BOY 22M injection moulding machine with referring to ASTM D638 where the dimensions were shown in Figure 1. Three parameters were chosen to be investigated, which were injection speed, injection pressure and mould temperature. Three levels were used for each parameter and can be tabulated as in Table 1 . The samples were produced with weld line incorporated. 


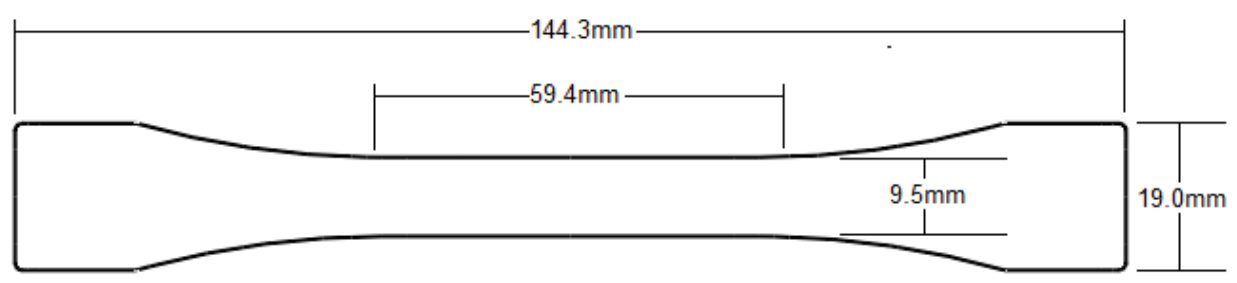

Figure 1: Dimensions of dumbbell sample.

Table 1: Processing parameters used and the respective assigned code.

\begin{tabular}{cccc}
\hline Code & Injection speed $(\mathrm{mm} / \mathrm{s})$ & Injection pressure $($ bar $)$ & Mould temperature $\left({ }^{\circ} \mathrm{C}\right)$ \\
\hline IS1 & 30 & 30 & 30 \\
IS2 & 50 & 30 & 30 \\
IS3 & 70 & 30 & 30 \\
IP1 & 30 & 30 & 30 \\
IP2 & 30 & 40 & 30 \\
IP3 & 30 & 50 & 30 \\
MT1 & 30 & 30 & 30 \\
MT2 & 30 & 30 & 40 \\
MT3 & 30 & 30 & 50 \\
\hline
\end{tabular}

\subsection{Tensile Testing}

Tensile testing was being done onto the obtained dumbbell samples according to ASTM D638. Grip distance of $60 \mathrm{~mm}$, gauge length of $50 \mathrm{~mm}$ and crosshead speed of $50 \mathrm{~mm} / \mathrm{min}$ were being used in the testing.

\subsection{Differential Scanning Calorimetry}

Differenntial Scanning Calorimetry (DSC) was conducted to measure the crystallinity of LDPE sample under various parameters. Specimens were cut and weighed to have $5-10 \mathrm{mg}$. The specimens were heated from $25^{\circ} \mathrm{C}$ to $200^{\circ} \mathrm{C}$ at a rate of $10^{\circ} \mathrm{C} / \mathrm{min}$. Peak temperature and enthalpies at crystallisation and melting were determined. The percentage crystallinity $\left(X_{c}\right)$ of LDPE can be calculated by:

$$
X_{c}=\frac{\Delta H_{m}-\Delta H_{c}}{\Delta H^{o}{ }_{m}} \times 100
$$

where, $\Delta \mathrm{H}_{\mathrm{m}}$ is the enthalpy of melting, $\Delta \mathrm{H}_{\mathrm{c}}$ is the enthalpy of cold crystallisation and $\Delta \mathrm{H}^{\circ}$ is perfect heat of fusion, which is $293.1 \mathrm{~J} / \mathrm{g}$ for LDPE. ${ }^{12,13}$ 


\subsection{Optical Microscopy}

The weld line region on the dumbbell samples were being observed under Dino-Lite AM413ZT handheld digital microscope at 50× magnification. The images captured were analysed by ImageJ software.

\subsection{Melt Flow Simulation}

3D model of the dumbbell sample was being drawn using SolidWorks according to the dimensions in Figure 1 with the thickness of $3 \mathrm{~mm}$. The 3D model was then loaded into CADMOULD to simulate the melt flow of LDPE inside the mould cavity.

\section{RESULTS}

\subsection{Tensile Strength and Degree of Crystallinity}

Figure 2 showed the tensile strength of LDPE samples underwent different processing conditions. It can be seen that the tensile strength of LDPE was increased by the increment of all of the investigated parameters, injection speed, injection pressure and mould temperature respectively. DSC was done onto the LDPE samples to obtain the degree of crystallinity of the samples as in Figure 3. LDPE is a semi-crystalline polymer and it is expected that the molecular chains will form a certain level of crystallinity at its normalised state and the degree of crystallinity will change according to the processing history it underwent. $^{14}$

Comparing Figures 2 and 3, it was found that the tensile strength of LDPE samples will increase with decreasing degree of crystallinity, as opposed to literature ${ }^{15}$ and research findings. ${ }^{16-18}$ There are probably two reasons for this, one of which is the tensile strength of LDPE investigated in this study is not highly dependent of the degree of crystallinity of the polymer itself, where it indicates that there are other properties that have higher influence onto the tensile strength of LDPE samples. Another reason would be the degree of crystallinity obtained from the DSC was inaccurate. Kong and Hay ${ }^{17,18}$ reported and cited from various sources that questioned the validity of DSC as a method to determine the degree of crystallinity of polymers where the results differ substantially from that determined by other analytical techniques. 


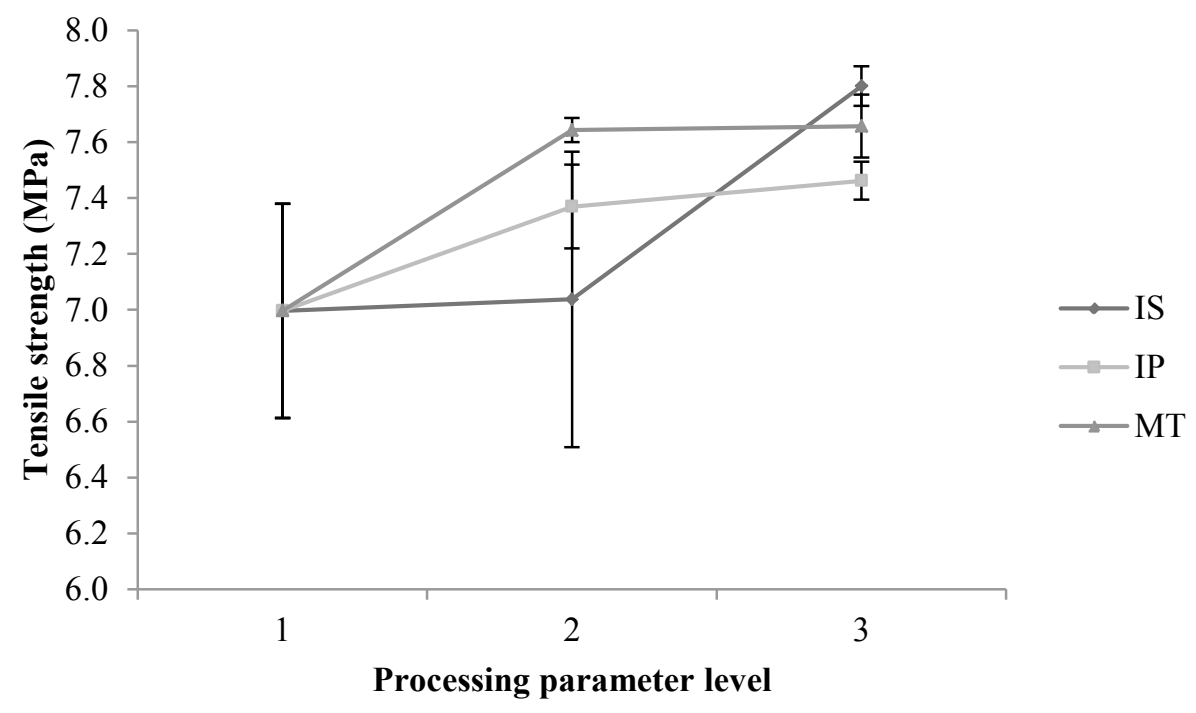

Figure 2: Tensile strength of LDPE samples from different parameters.

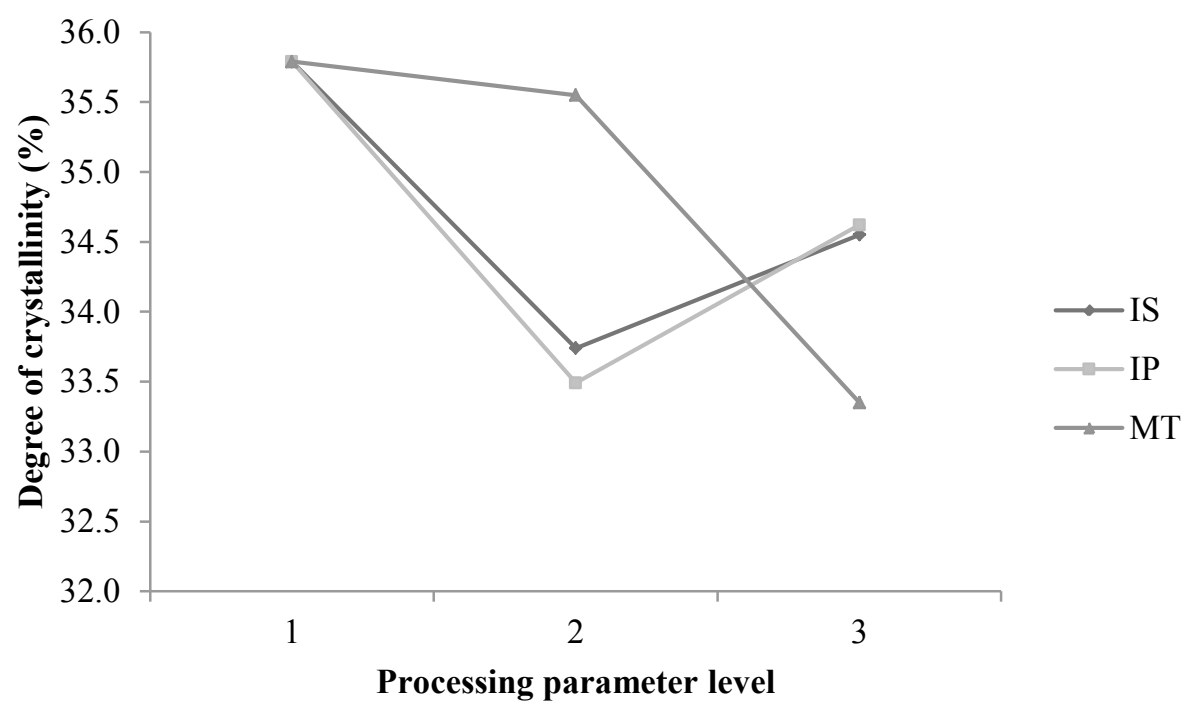

Figure 3: Degree of crystallinity of LDPE samples from different parameters.

\subsection{Evaluation of Tensile Strength by Weld Line}

Since the degree of crystallinity was found to be having inverse effect on the tensile strength of LDPE and contradicted what researchers had established; addition of the claim of inaccuracy of the DSC for determining degree of 
crystallinity, the tensile strength of dumbbell samples with weld line can be evaluated by examining the weld line itself. Figure 4 showed the weld line region of dumbbell sample under ordinary camera and the zoomed image at $50 \times$ magnification. The measurement of the thickness of the weld line can be seen in Figure 5 with respect to different processing parameters. Thinner weld line indicates that the melt flow from two different directions meet and diffuse together better compared to thicker weld line. Comparing Figures 2 and 5, it can be seen that the thinner weld line, the stronger the dumbbell samples will be.

It can be seen from Figure 5 that the weld line on the dumbbell samples was getting thinner as the injection speed, injection pressure and mould temperature increase, indicating the tensile strength of the pieces getting stronger. Similar results were being reported by $\mathrm{Wu}$ and Liang. ${ }^{19}$ Being processed at higher injection speed made the polymer melt fronts experienced higher shear stress and thus the diffusion of the melt fronts increased, giving rise to a stronger weld line. In the case of injection pressure, higher pressure gave to higher packing of the polymer melt at the weld line and produced a thinner weld line. As for mould temperature, high mould temperature provided more time before solidification for the polymer melt to diffuse and for the polymer chains to entangle between each other, giving a stronger weld line.

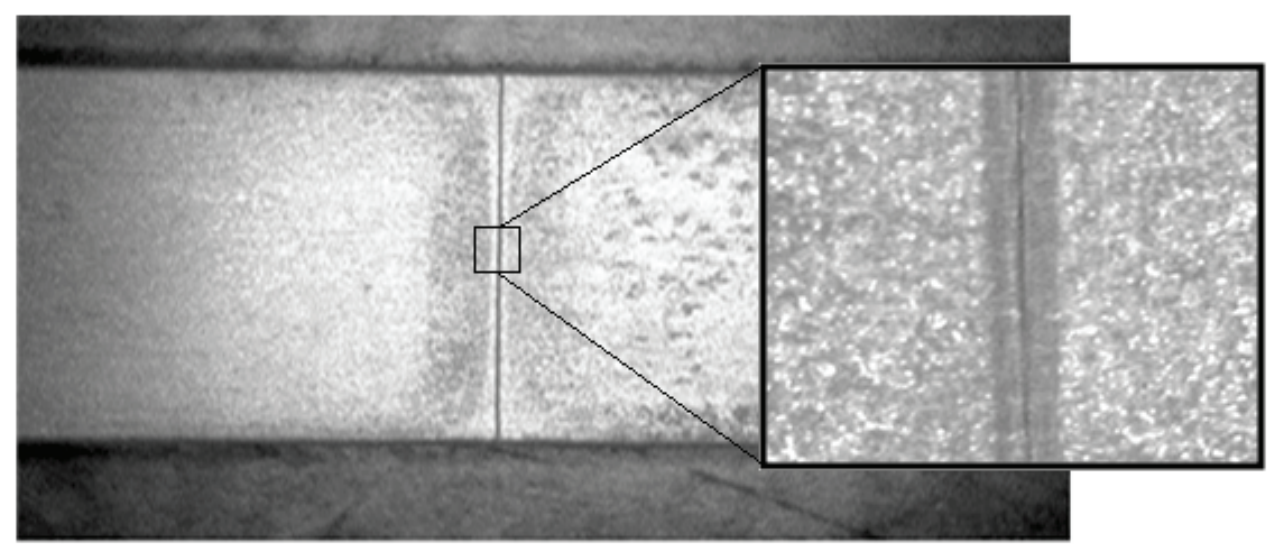

Figure 4: Weld line of dumbbell sample under 50× magnification. 


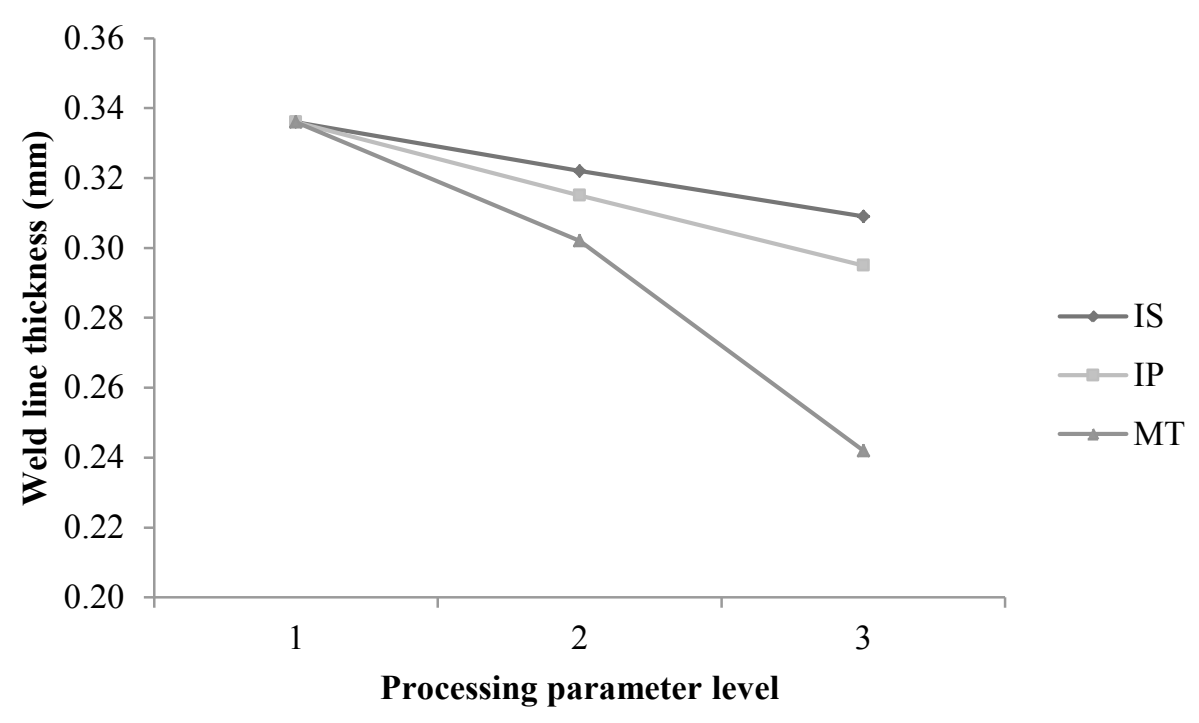

Figure 5: Thickness of weld line from different parameters.

\subsection{Evaluation by Simulation}

Figure 6 showed the simulation of filling of the dumbbell samples by CADMOULD software. Lines propagate across the dumbbell sample indicating the flow of polymer melt inside the mould cavity. The region near the weld line was magnified and inspected for the diffusion of two melt fronts at the weld line. In the zoomed image in Figure 6, arrows showed the flow direction of polymer melts and the place where the arrows turned horizontal indicated where the weld line should be. Figure 6 showed the simulation of time of filling in the simulation and by fixing the line per element in the simulation as a constant; the speed of the melt fronts can be estimated by counting the distance between each line. The relationship can be shown as:

$$
\text { Estimated speed }=\frac{\text { distance between line }}{\text { time }(\text { line per element })}
$$

The distance between lines, measured in pixel, is directly proportional to the speed of melt flow and as explained above the higher speed will result in thinner and stronger weld line. 


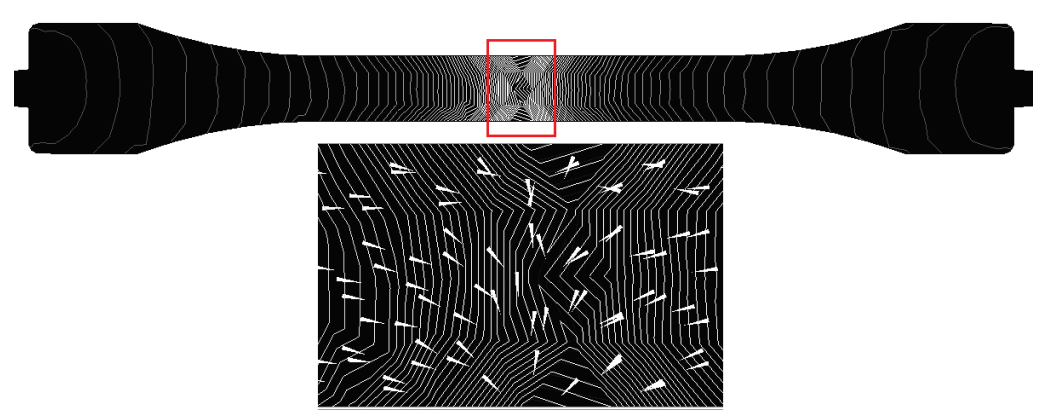

Figure 6: Simulation of time of filing of the polymer melt in dumbbell sample.

The measured distance between lines of the simulation was shown in Figure 7. It can be seen that the increment in injection speed, injection pressure and mould temperature all caused the distance to increase. This simulation showed that the polymer melt flow speed will increase with the increasing of the three parameters, and consequently increase the strength of the weld line formed on the dumbbell samples, as shown in Figure 2. Figures 2, 5 and 7 showed that the weld line thickness and distance of flow lines in simulation are in good agreement, although in inverse relationship, and could be used to evaluate the tensile strength of the dumbbell samples with weld line. The simulation result from CADMOULD perhaps can be used to predict the strength of a polymer product, without the need of production of testing samples and wastage of materials.

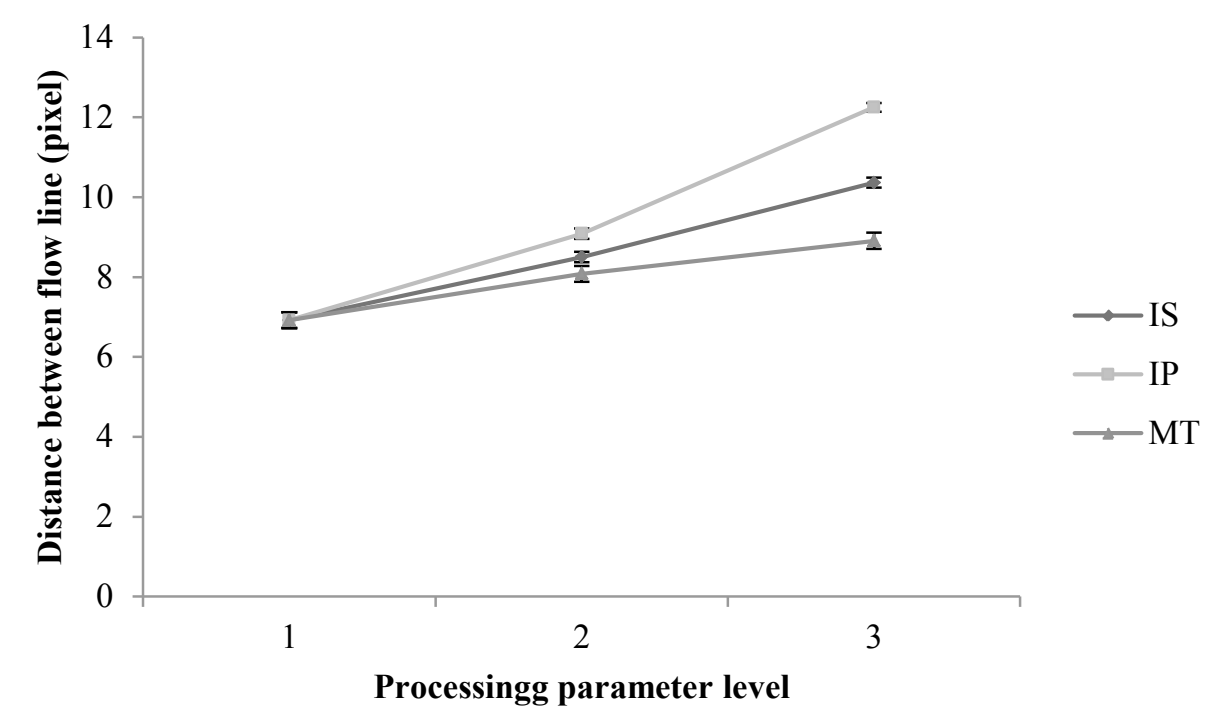

Figure 7: Distance between flow lines of the simulated result. 


\section{CONCLUSION}

The increment in injection speed, injection pressure and mould temperature during injection moulding will increase the tensile strength of the samples moulded. Although the degree of crystallinity is known to change with different processing conditions and is related to the tensile strength, but it did not show a clear trend to be correlated with the tensile strength, and probably was due to the inability of the DSC analysis to accurately record changes in crystallinity within the sample since molecular orientation can vary with the thickness of the sample. On the other hand, the measurement of thickness of weld line under optical microscope and the evaluation of CADMOULD simulation showed a solid relationship with the tensile strength. It was found that the thinner the weld line, the stronger the weld line will be. Measurement of the distance of flow lines in CADMOULD simulation can also be used to predict the tensile strength of the samples simulated.

\section{ACKNOWLEDGEMENT}

The related work in this paper was sponsored by Universiti Sains Malaysia through Fundamental Research Grant Scheme, reference number FRGS/1/2014/TK04/02/1.

\section{REFERENCES}

1. Holbery, J. \& Houston, D. (2006). Natural-fiber-reinforced polymer composited in automotives applications. JOM, 58(11), 80-86, https://doi.org/10.1007/s11837-006-0234-2.

2. Rosato, D. V. \& Rosato, M. G. (2012). Injection moulding handbook. 3rd ed. New York: Springer Science \& Business Media.

3. Kwon, K. et al. (2006). Theoretical and experimental studies of anisotropic shrinkage in injection mouldings of semicrystalline polymers. Polym. Eng. Sci., 46(6), 712-728, https://doi.org/10.1002/pen.20546.

4. Breuer, G. \& Schausberger, A. (2011). Recovery of shear modification of polypropylene melts. Rheol. Acta, 50(5), 461-468, https://doi.org/10.1007/s00397-011-0542-5.

5. Leblans, P. J. R. \& Bastiaansen, C. (1989). Shear modification of lowdensity polyethylene: Its origin and its effect on the basic rheological functions of the melt. Macromolecules, 22(8), 3312-3317, https://doi.org/10.1021/ma00198a020. 
6. Hee, S. M. et al. (2001). Effect of shearing on crystallization behavior of poly(ethylene terephthalate). J. Appl. Polym. Sci., 80(14), 2640-2646, https://doi.org/10.1002/app.1377.

7. Peacock, A. J. \& Calhoun, A. R. (2006). Polymer chemistry: Properties and applications. München, Germany: Carl Hanser Verlag, https://doi.org/10.3139/9783446433434.

8. Olmsted, B. A. \& Davis, M. E. (2001). Practical injection moulding. New York: Marcel Dekker, Inc.

9. Roland, C. M. \& Robertson, C. G. (2006). Recovery of shear-modified polybutadiene solutions. Rubber Chem. Technol., 79(2), 267-280, https://doi.org/10.5254/1.3547937.

10. Vietri, U. et al. (2011). Improving the predictions of injection moulding simulation software. Polym. Eng. Sci., 51(12), 2542-2551, https://doi.org/10.1002/pen.22035.

11. Pantani, R. \& Sorrentino, A. (2005). Pressure effect on viscosity for atactic and syndiotactic polystyrene. Polym. Bull., 54(4), 365-376, https://doi.org/10.1007/s00289-005-0397-y.

12. Kazimi, M. R. (2014). Characterization of functionalized low density polyethylene/polyaniline nano fiber composite. J. Med. Bioeng., 3(4), 306-310, https://doi.org/10.12720/jomb.3.4.306-310.

13. Blaine, R. L. (n.d.). Polymer heats of fusion. New Castle, DE: TA Instruments.

14. Godovsky, Y. K. (2012). Thermophysical properties of polymers. New York: Springer Science \& Business Media.

15. Gilmore, C. (2014). Materials science and engineering properties. Stanford, CA: Cengage Learning.

16. Sarasua, J. R. et al. (2005). Crystallinity and mechanical properties of optically pure plylactides and their blends. Polym. Eng. Sci., 45(5), 745753, https://doi.org/10.1002/pen.20331.

17. Kong, Y. \& Hay, J. N. (2002). The measurement of the crystallinity of polymers by DSC. Polymer, 43(14), 3873-3878, https://doi.org/10.1016/S0032-3861(02)00235-5.

18. Kong, Y. \& Hay, J. N. (2003). The enthalpy of fusion and degree of crystallinity of polymers as measured by DSC. Eur. Polym. J., 39(8), 1721-1727, https://doi.org/10.1016/S0014-3057(03)00054-5.

19. Wu, C. H. \& Liang, W. J. (2005). Effects of geometry and injectionmoulding parameters on weld-line strength. Polym. Eng. Sci., 45(7), 1021-1030, https://doi.org/10.1002/pen.20369. 